\title{
The History of Base-Ten-Blocks: Why and Who Made Base-Ten-Blocks?
}

\author{
Rina Kim \\ Lillie R. Albert \\ Boston College \\ Email: rina@bc.edu and albertl@bc.edu
}

\section{Doi:10.5901/mjss.2014.v5n9p356}

\begin{abstract}
The purpose of this study is to present evidence of how base-ten-blocks have been developed and emphasized as a tool for learning in mathematics education. After an introduction of the theme, we discuss the theoretical and epistemological perspectives that provide the basis for our analysis of the literature. Then, we illustrate how base-ten-blocks have historically been associated with the numeral concepts from the prehistoric era to today. We also review studies about different manipulatives that focus on numerical concepts (e.g., Cuisenaire rods). This discussion will broaden our understanding regarding how perspectives toward mathematics instruction have changed with the introduction of base-ten-blocks. The intent was not to understand the process of developing base-ten-blocks but rather to suggest that teachers must consider the underlying mathematical concepts and structures of base-ten-blocks when they use them. In summary, this study revealed that base-ten-blocks as concrete materials seems to have been presented as different isomorphic numeral concepts for various educational purposes throughout its developmental process.
\end{abstract}

Keywords: Base-ten-blocks; manipulatives; elementary mathematics education;

\section{Introduction}

Much has been stated about the mediating role of manipulatives in mathematics education. For example, Seefeltdt and Wasik (2006) asserted that manipulatives might foster students' understanding of mathematics concepts. Among diverse mathematical manipulatives, the use of base-ten-blocks might be the key for supporting elementary students' learning of numbers, because they are useful when demonstrating an abstract mathematical concept of the number system such as one-to-one correspondence, place value, and basic addition and subtraction (Bartolini, 2011; Fuson, 1990; Harrell, 2009). However, recent studies have pointed out that it may not be helpful to young children if a teacher does not understand the mathematical meaning of base-ten-blocks (Green, 2008; Tare, 2010).

The purpose of this study is to provide a framework for understanding the mathematical meaning of base-tenblocks based on the process of their development. This also might offer an extended metaphor of base-ten-blocks as a bridge for connecting abstract numeric concepts with visualized models. To illustrate this point, we provide evidence of the influence of different types of base-ten-blocks in mathematics education throughout history. We consider not only the history and mathematical meaning of base-ten-blocks that are used in a mathematics classroom currently, but also mathematical tools that may relate to numeric concepts that were used in the prehistoric era. It is important to note how mathematics concrete materials that might represent numeric information may have had different meanings throughout history. Currently, base-ten-blocks are considered as one type of manipulatives that support students' modeling abstract numeral concepts. In the prehistoric era, the prototype of base-ten-blocks may have been developed as a vehicle through which people might visualize abstract numeral concepts as an observable form of communication. Although there are limited mathematics instructional purposes in the prototype of base-ten-blocks, it might be helpful to broaden our understanding of the relationship between mathematics concepts and tools that represent them.

In this study, we will reflect on how base-ten-blocks have been intertwined with mathematical concepts based on a review of the literature. In reviewing a significant part of the literature that deals with the role of base-ten-blocks in the production of teaching and learning, we hope to demonstrate how base-ten-blocks have been the focus of discussion in mathematics education at the elementary level. To add to the historical perspectives of the connection between base-tenblocks and their mathematical meaning, we also take a brief detour into different manipulatives that focus on concepts of numbers (e.g., Cuisenaire Rods) and mathematical discussions about them in the history of mathematics education. To develop our analysis, we first present our theoretical perspectives regarding the relationship between base-ten-blocks 
and mathematics concepts in the following section.

\section{Theoretical Perspectives}

The analysis presented in this study is supported by theoretical views that base-ten-blocks may take the role of intermediary between the real world and the mathematical world (Lesh, 1979). The number only exists in the mathematical world, since it is an abstraction; we may see illustrations of the number in the real world, but we do not see the concept itself. Young (1983) pointed out that manipulatives such as base-ten-blocks might help young children understand the concepts in the mathematical world based on their structural similarity to abstract concepts. Post (1977) used the term isomorphic (p. 5) to represent the similarity between the mathematical world and the real world. Post argues that isomorphism is significant in students' mathematics learning, since it may transform an abstract concept into an accessible form in the students' real-life. However, it is significant to acknowledge that manipulatives may represent only a part of an abstract mathematics concept (Post, 1977). For example, there are various real world situations to demonstrate the number 2, as shown in Figure 1. Among diverse mathematical concepts that may relate to the number 2, teachers may use base-ten-blocks to explain isomorphism that emphasizes discrete quantities of 2.

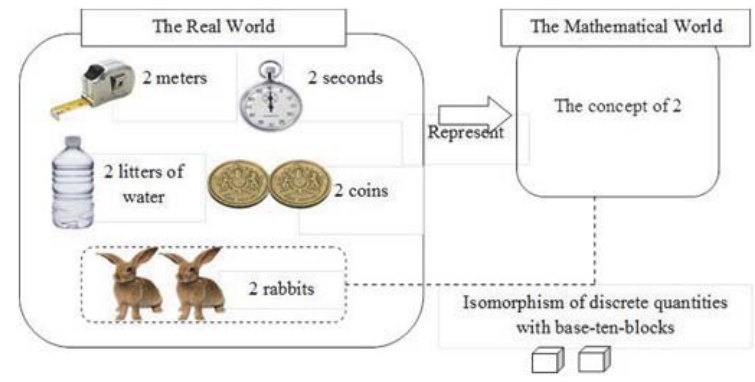

Figure 1. Isomorphism of the mathematics concept.

Thus, it is important for teachers to understand the isomorphism between base-ten-blocks and mathematical concepts of numbers. As noted by Post (1977), "the extent to which partial isomorphism approximates the concept is the extent to which the more accessible structure is useful in teaching the concepts" (p. 332).

Another significant epistemological viewpoint of this study is that tools or materials may produce mathematics concepts (Borba \& Villarreal, 2005). This notion is based on the idea that mathematics concepts are not an individual enterprise, and tools or materials are essential elements of mathematics concepts (Villarreal \& Borba, 2009). The process of developing a specific teaching tool may include complex interactions between pedagogical theories, mathematical ideas, instructional purposes, and teaching techniques (Kidwell, Ackerberg-Hasting \& Roberts, 2008). Thus, diverse tools and materials might be related to various mathematics concepts, and concrete materials in the past are useful to reveal how mathematics concepts have developed over time. Revealing the past that lies behind base-ten-blocks may help us understand how they reflect a wide range of discussions about teaching numerical concepts to students. Thus, we will analyze the development process of base-ten-blocks with observations of different concrete materials used during the prehistoric era, in the following section.

\section{Concrete Materials for Representing Numbers and Mathematics}

It is an interesting exercise to observe diverse concrete materials that represent numeral concepts in the prehistoric era because they show how collectives of humans with concrete materials produced numeral concepts. In particular, ancient concrete materials might demonstrate that numeral concepts were developed based on the concept of one-to-one correspondence. One-to-one correspondence is a mathematical function offering pairings of elements in two sets. With this concept, prehistoric mankind may have represented numbers of things by making marks to symbolize amounts. For example, the carved marking on Ishango bones from Africa, believed to be more than 20,000 years old, show that prehistoric mankind had a mathematical understanding of one-to-one correspondence (Brooks \& Smith, 1987; Rudman, 2007). Although there are various approaches to understanding the meaning of marks mathematically (e.g., Gerdes, 1991; Rudman, 2007), one thing is clear: Prehistoric mankind carved marks according to the amount of something in order to represent numeral information based on one-to-one correspondence, as shown in Figure 2. 


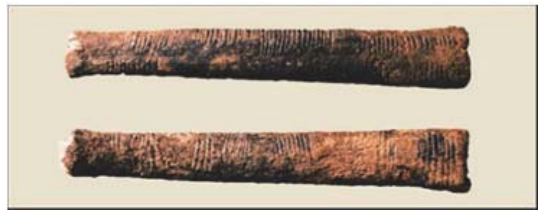

Figure 2. Ishango Bones from Africa (Kim, 2012, p. 16).

Finger numerals used by the ancient Greeks, Romans, Europeans of the middle ages, and later, the Asiatic also demonstrate prehistoric mankind's understanding of numeral concepts based on one-to-one correspondence (Dantzig, 2005). As illustrated in Figure 3, people developed different shapes of fingers according to each number. Although we may not say that fingers are concrete materials, finger numerals also illustrate that the early concept of numbers might have emerged from the concept of one-to-one correspondence.

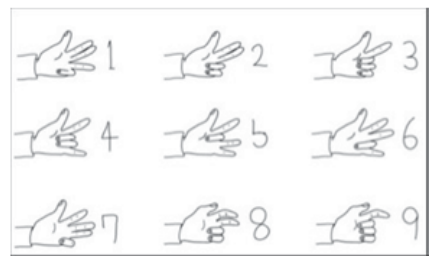

Figure 3. Finger numbers (Kim, 2012, p. 17).

Further interesting evidence of concrete materials that have been associated with mathematics historically comes from quipu. Quipu (or khipus) usually consisted of colored thread or string and was a recoding method used in the region of Andean South America. Quipu flourished across the Andes from around 1450 B.C. to A.D. 1532, but it faded from use after the Spanish Empire invaded. Quipu records numeric information through the making of knots (Roberts, 2001). The preliterate notation of numbers by rope knots showed not only the numeric concept of one-to-one corresponding, but also described the concept of equal increments in an increasing amount according to the numbers (Roberts, 2001). Unlike the current number system, which uses ten different symbols for each digit (0 to 9), quipu manufacturers tangled several knots in a tight sequence to represent a digit. Digits might range from empty knots representing zero, to nine knots representing nine. Quipu demonstrated the basic approach of expressing numeric information by adding a certain amount of a unit. Representing numbers by an equally incremented amount with a knot is akin to current base-ten-blocks. In addition, we may observe the basic concepts of a ten-based number system and place values. The location of knots represents place values. As shown in Figure 4, the number 342 would be represented as three sequences of knots, the first one with three knots, the second with four knots, and the last one with two knots.

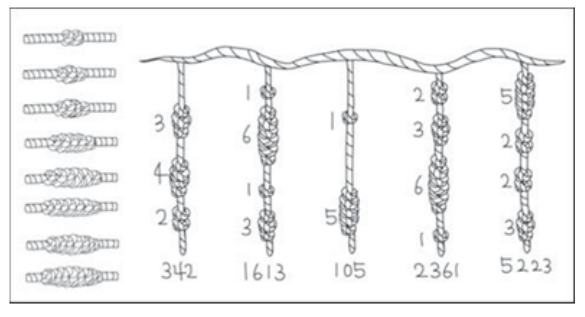

Figure 4. Quipu (Kim, 2012, p. 19).

The detour into concrete materials in the prehistoric era illustrates how mathematical concrete materials have historically been associated with the production of numeral concepts. The analysis of ancient concrete materials may reveal that the numeral concepts emerged associating with the concept of one-to-one corresponding from the beginning. The discussion in this section may provide some clues regarding how we may use base-ten-blocks in a mathematics classroom to 
represent the mathematics concept of one-to-one corresponding. However, it does not indicate that the mathematical concrete materials might be used for developing students' numeral concepts without mathematics instructions, although we have identified the presence of concrete materials representing numeral concepts in ancient mathematics. As discussed in the previous section, mathematical concrete materials might be used to produce mathematical knowledge according to the way people employ them. Subsequently, when did people start to use concrete materials in mathematics instruction to teach numeral concepts to students? In the sections that follow, we discuss the history of base-ten-blocks by examining how concrete models were introduced to the classroom in the period of Naturalism during the eighteenth century.

\section{Concrete Materials for Representing Numbers and Mathematics Education in the Period of Naturalism}

As society has developed, the representation of numbers has evolved into the use of symbols, such as Arabic Numbers. Concrete materials emerged in the developmental process of numeric symbols and gradually changed into numbers, although some concrete materials are still used for calculating (e.g., an abacus in Roma or China) (Cajori, 1930). In particular, after the era of Euclid, mathematics educational approaches had converged into conveying logical and formal mathematics knowledge to students, and no evidence was found that teachers use specialized concrete materials to teach numeral concepts in their mathematics classroom in the era of Euclid (Cajori, 1901; Vianna, 2010). Thus, the introduction of concrete materials might be a significant watershed in the fields of mathematics education because this might indicate that the center of mathematics education changed from teachers to students, since the era of Euclid (Herrera, 2001). The origin of this change might be founded in Naturalism, which emphasizes the behavior of the natural universe (Landman, 2001; Rosen, 1999). Naturalism primarily originated in the idea of medieval scholars during the Renaissance of the twelfth century (Post, 1995). Naturalism assumes that children's learning does not depend on teachers' explanations in a classroom or books. Instead, it focuses on learning based on manipulation of the real life of students (Landman, 2001; Rosen, 1999). Although teaching children how to count with familiar things was not new in this era, using specialized concrete materials to teach numeral concepts was a remarkable change in mathematics instruction.

Naturalism's principles and views on education laid the foundation for the modern education system (Butler, 1951; Dame, 1938; O'Connell, 1938; Punke, 1965). In addition, Naturalism had a pivotal role in developing diverse materials for teaching. For instance, Comenius, a pioneer of Naturalism, developed Ortis Pictus, which is considered to be the first picture book intended for children (Dooley, 1991). Rousseau suggested that children should learn with direct physical contact rather than learning with a book (Davidson, 1971). Another Naturalist, Pestalozzi, also emphasized object lessons (Gutek, 1968). Gladman (1886) represented well the basic concepts of lessons with concrete materials in his book School Works, as follows:

Objective illustration, in which the eye and the other organs of sense are directly appealed to, and called in to help the verbal exposition, is almost always the best means of clearing up. Nothing aids the formation of clear ideas about things like actually seeing and handing the objects themselves. (p. 120-121)

Naturalism had significant effects on the introduction of learner-centered mathematics education that emphasizes the use of diverse materials. Accordingly, the development of concrete materials for teaching numeral concepts in mathematics education became active in the era of Naturalism. Parents and teachers taught children to count familiar things in this era, although there were no concrete materials specifically designed to teach children basic mathematics concepts though manipulation. For example, Pestalozzi and his disciples advised teachers and parents to provide children with dried beans or other simple objects as they learned to count (Kidwell et al., 2008).

Froebel laid a foundation for developing ways of teaching numeral concepts with concrete materials (Bowen, 1893). Although it might not be anything new for children to play with concrete materials, Froebel's approaches to the use of concrete materials in teaching was new in those periods (Manning, 2005). Froebel designed concrete materials named gifts and activities called occupations (Froebel \& Lilley, 1967). Gifts consisted of a series of activity-based objects ranging from simple sphere-shaped ones to geometric wooden blocks. In particular, Froebel suggested that concrete materials should bridge the gaps among mathematics concepts, perceptions, and thoughts (Fennema \& Romberg, 1999) and used gifts to support students' understandings of the basic concepts of geometry, counting, and the relationship between the parts and the whole (Brosterman, 1997). For example, Froebel used third gifts, which was a set of eight identical cubes, for representing simple ideas about numeral concepts and basic algebra, such as addition and subtraction (see Figure 5; Kidwell et al., 2008). 


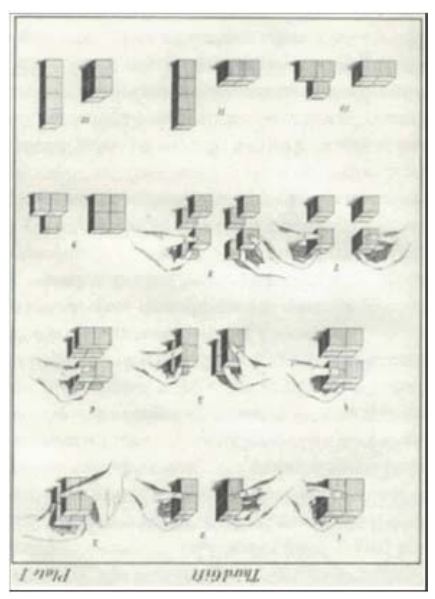

Figure 5. Froebel's third gift (Wiebé, 1869, pl. 1).

Wiebé's (1869) explanation of how to use gifts in mathematics education may illustrate that teaching numbers were associated with counting discrete quantities in this era:

They instruct the pupil concerning the properties and relations of numbers, by a particular arranging and grouping of the blocks. Strictly speaking, the first effort to count, by laying them on the table one after another, is to be classed under this head...Proceeding further, he is taught to add, always by using the cubes to illustrate the successive steps. Thus, having placed two of the blocks at a little distance from each other on the table, he is caused to repeat, "One and one are two" (Wiebé, p. 14).

Although teachers might use gifts to teach the basic concept of numbers, Froebel's gifts had limitations for demonstrating diverse numeral concepts such as the place-value system because they were developed not only for mathematics education, but also for the general education of children.

Montessori, who also was affected by Naturalism, emphasized the use of concrete materials for teaching number concepts to students (Larson, 2010; Lillard, 2006). Although Montessori's teaching methods with concrete materials were more famous than concrete materials themselves, she developed the first elaborate and systemic concrete materials for mathematics education such as colored bead bars and ten-based bars (see Figure 6) (Larson, 2010). Montessori's colored bead bars are a series of beads on stiff wired bars. They are numbered one through nine, and each number has a different color. These bars can be used for number recognition as well as counting.

Figure 6. Montessori's colored bead bars.

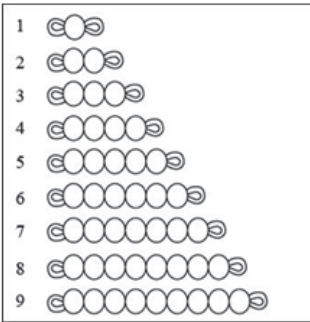

Similarly to Froebel, Montessori argued that concrete materials should be used as mediators between mathematics concepts and students' understanding based on their real lives, in mathematics education. Based on this assumption, Montessori developed educational concrete materials called sensorial materials that lead to the understanding of abstract concepts (Larson, 2010; Lillard, 1973; Standing, 1959). Montessori's colored bead bars and chains of beads were concrete materials much like today's base-ten-blocks, although students could not break the bars into individual beads. Montessori used them only for teaching how to count numbers and the names of each number. They were used in different ways: colored bead bars for teaching numbers from one to nine, and ten bars for multiples of ten. Although 
Montessori did not classify her tools as isomorphic, it is interesting that colored bead bars could be used for representing continuous quantities. We can represent discrete quantities with beads, themselves. However, Montessori changed the isomorphism of the beads by connecting them with solid wire.

Both Froebel and Montessori's works highlighting children's activities with concrete materials provide some clues for understanding the relationship between children's perception and comprehension of numbers. Also, they both had the effect of using peculiar objects for mathematics education for children. For example, Thorndike, a behavioral psychologist, used cubes to teach the amounts represented by numbers in his book The Psychology of Arithmetic (see Figure 7 ; 1922).

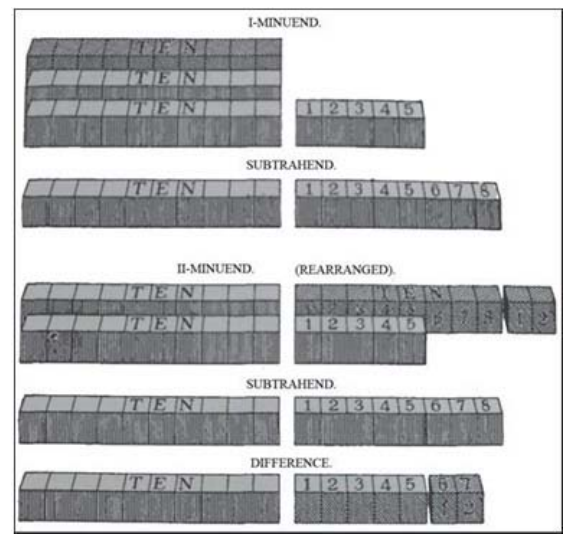

Figure 7. Thorndike's cube picture (Thorndike, 1922, p. 250).

However, at the turn of the twentieth century, their attempts to use concrete materials in child education had declined because they were nonscientific and they overemphasized personal activities (Kilpatrick, 1914). In addition, both Froebel and Montessori's concrete materials were not enough for teaching mathematic concepts of numbers because they were focused on naming and counting numbers based on one-to-one corresponding, which were only parts of the number concepts.

\section{Concrete Materials for Representing Numbers and Mathematics Education in the Period of the New Math Movement}

After Froebel and Montessori, the development of base-ten-blocks began to become active with the New Math Movement in the 1960s (Kidwell et al., 2008). Before the era of the New Math Movement, teachers did not focus on teaching the basic concepts of mathematics to their students, because mathematics instruction had emphasized how to use math skills in daily life rather than understanding the basic concepts (Bester, 1953). In contrast, mathematics education in the era of the New Math Movement focused on systemic mathematical concepts with the precise and definitive terms and structure of mathematics (Howson, 1981). Although the New Math Movement did not guarantee success, the approaching structure of mathematical knowledge had changed basic concepts of teaching and learning mathematics (Bruner, 1971). Subsequently, the development of concrete materials in mathematics education after the 1960s might be comprehended with respect to both its significant effect and its reverberation of the New Math Movement-reflecting the structure of mathematics and students' participation in operating materials. Bruner (1971) pointed out that traditional mathematics instruction overemphasized the superficial facts and results of mathematics, and proposed that the basic concepts, principles, and ideas inherent to the structure of mathematics should be accentuated. Piaget (1968) also claimed that students might obtain mathematical or logical forms of abstraction by acting or operating on things, which reflects the basic concepts and properties of mathematics. In particular, Bruner (1960) argued that model devices, such as Cuisenaire rods or base-ten-blocks, can lead students to improve their sense of conceptual mathematics structure of the numeric system. Specifically, there became diverse shapes of base-ten-blocks after the New Math Movement: the unit blocks, the Cuisenaire rods, the color-factor set, and the multi-base arithmetic blocks. We present the four major shapes of base-ten-blocks in this section in chronological order with discussions of the mathematical meanings of the models. 
Stern claimed that a structural approach toward arithmetic is crucial because arithmetic skills follow naturally from the structural properties of the number system (as cited in Mock, 1973). Stern and Stern (1948) argued that students should learn number sense as a basic structure of numeral concepts as well as the art of counting based on one-to-one correspondence. Stern and Stern (1948) define number sense as "based on the fact that a number of objects may be arranged to make a characteristic pattern, which is changed when objects are added or subtracted. Primitive men may have used many such natural model collections" (p. 2). Stern designed the counting board and the unit blocks in order to grow students' number sense, as illustrated in Figure 8 (Horner \& Patterson, 2008). Stern and Stern (1948) asserted that students should develop basic number senses such as sequence and values of each number, and a pair of numbers that makes ten with these materials, before they learn the name of each number.

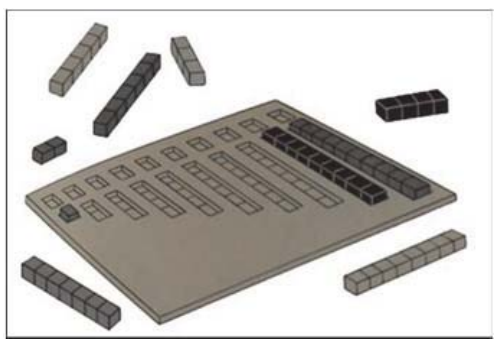

Figure 8. Stern's counting board (adapted from Stern \& Stern, 1948, p. 25).

The authors also point out that students may connect each number with numeric information when they have experience with values of numbers. To represent large numbers, Stern developed devices that represent the structure of the tenbase system. Stern and Stern (1948) used it for teaching place values. Although they did not use the terms for naming base-ten-blocks such as bars or cubes, the blocks Stern promoted for teaching have been sold under the name base-tenblocks, as shown in Figure 9 (Ruth, 1926).

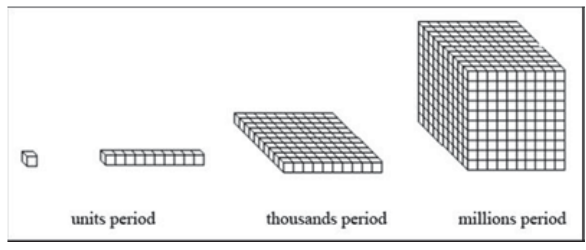

Figure 9. Stern's concrete model for place values (Stern \& Stern, 1948, p. 347).

Cuisenaire and Gattegno (1961) also suggested that students have to have an experience with values of numbers before they learn the number names. They proclaimed that students could develop understanding, reckoning, and verifying numbers through manipulating concrete materials. Cuisenaire developed the Cuisenaire rods to cultivate students' number senses; however, Cuisenaire and Gattegno focused on the diverse relationships among numbers as well as the numeric information of each number, as illustrated below:

Cuisenaire came to the conclusion that the learning of arithmetic could be greatly simplified through the use of rods of from 1 to 10 centimeters in length colored as follows: red family: vermilion (2), crimson (4) yellow family: yellow (5), orange (10); black (7); white (1). Even within one color family there may already exist a variety of number relationships, e.g. $2,2+2=4,2 \times 2=4,4+4=8,2 \times 4=8,2=\frac{1}{2} 4,4=\frac{1}{2} 8,2=\frac{1}{4} 8$, etc. (Cuisenaire \& Gattegno, 1961, p. 5)

Similar to Cuisenaire's rods, Pollock (1962) developed color-factor bars. However, Pollock focused more on the relationships among numbers than making students understand the numeric information of each number. Pollock used a twelve-based system in his color-factor set in order to represent the relationship among numbers clearly, such as multiples, divisors, and square numbers (see Figure 10). In addition, Pollock used color to replace the names of numbers and represent the relationships among numbers; Pollock set up a basic four colors and used them for representing prime number bars under twelve. Pollock defined the colors of the rest of the number bars by mixing colors of prime number bars. 


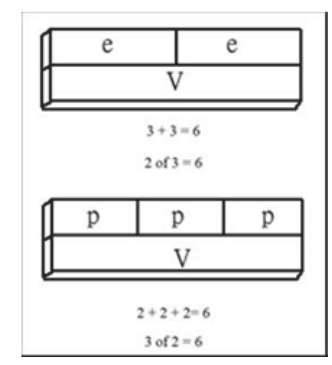

Figure 10. Pollock's color-factor bars (adapted from Pollock, 1962, p. 31).

Dienes affirmed that the presentation of mathematical symbols tended to be introduced at too early of a stage in school mathematics education (Hirstein, 2007). Also, Dienes (1963) proclaimed that teaching materials should be used based on the mathematical subjects rather than students' developmental stages based on their ages. From his assumption, Dienes (1963, p. 27) designed multibase arithmetic blocks (MAB) with an emphasis on the basic concepts of the number system; $M A B$ provides concrete representations for the number bases. The most notable point of MAB is to apply basic principles of the number system as a structure of mathematics concepts regardless of the number for base. If the base is equal to $n$, the sum of $n$ Units becomes Long, the sum of $n$ Longs becomes Flat, and the sum of $n$ Flats becomes Blocks. The name of each Block is denoted by the following abbreviations:

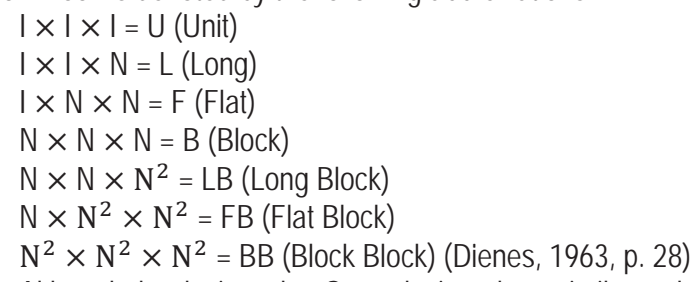

Although the devices that Stern designed are similar to the current base-ten-blocks in their forms and functions, the most salient point in this era is to understand the structures of mathematics that the different shapes of base-ten-blocks represent; the relation among numbers such as fraction, multiple, divisor, or system of numbers like decimal or binary system. In addition, the instruction of base-ten-blocks may differ depending on the mathematics educational purpose. Cuisenaire suggested that students might use devices before they learn names of each number (Cuisenaire \& Gattegno, 1961). Otherwise, Stern asserts that teachers may use her device before or after teaching names of numbers based on the structure of numbers that teachers are willing to teach (Stern \& Stern, 1948).

Subsequently, why are the base-ten-blocks so widely used? The patronage for education and the invigoration of professional organizations in the late 1950s may provide some clues to explain the propagation of base-ten-blocks (Kidwell, et al., 2008). From the late 1950s, the federal government offered funds for the purchase of teaching materials in schools, and diverse mathematics materials were propagated, along with textbooks, due to this economic support. Stern provided her materials with a textbook titled Experimenting with Numbers: Teacher's Manual for Use with Beginners, and Cuisenaire also built his own company and made strong claims for the Cuisenaire Rods (Roberts, 2001). The professional organizations of mathematicians and mathematics teachers invigorated schools to improve their use of teaching materials, such as the Mathematical Association of America (MAA) and the National Council of Teachers of Mathematics (NCTM). Their activities inspired rich discussions of materials for teaching (Kidwell, et al, 2008).

\section{Concluding Comments}

According to the Representation Standard in Principles and Standards for School Mathematics, "instructional programs from pre-kindergarten through grade 12 should enable all students to use representations to model and interpret physical, social, and mathematical phenomena" (NCTM, 2000, p. 136). In particular, base-ten-blocks may provide a proper model of the number system and the concepts of place values to students. Students may observe the complex relationship among numbers such as multiples, divisors, and square numbers. In this case, the most pivotal point of using base-tenblocks is that teachers should understand how the structure of numeral concepts could be exemplified by using base-ten- 
blocks.

To reveal the mathematical structure that base-ten-blocks can include, we have presented a review of literature on the history of base-ten-blocks that presents discussions in the field of mathematics education. The intent was not to understand the process of developing base-ten-blocks but rather to suggest that teachers must consider the underlying mathematical concepts and structures of base-ten-blocks when they use them. In summary, this study revealed that base-ten-blocks as concrete materials seems to have been presented as different isomorphic numeral concepts for various educational purposes throughout its developmental process. In addition, the history of base-ten-blocks reflects new educational ideas and changing views of mathematics education. We believe that the analysis developed in this study can help us understand mathematics education as well as how mathematics instruction might be better structured with the use of base-ten-blocks.

\section{References}

Bartolini, B. M. (2011). Artifacts and utilization schemes in mathematics teacher education: Place value in early childhood education. Journal of Mathematics Teacher Education, 14(2), 93-112.

Bestor, A. (1953). Educational wastelands: The retreat from learning in our public schools. Urbana: University of Illinois Press.

Borba, M., \& Villarreal, M. (2005). Humans-with-media and the reorganization of mathematical thinking: Information and communication technologies, modeling, experimentation and visualization. Mathematics education library (Vol. 39). USA: Springer Science+Business Media.

Bowen, H. (1893). Froebel and education by self-activity. New York: Charles Scribner's Sons.

Brooks, A. S., \& Smith, C. C. (1987). Ishango revisited: New age determinations and cultural interpretations. African Archaeological Review, 5(1), 65-78.

Brosterman, N. (1997). Inventing kindergarten. New York: Harry N. Abrams.

Bruner. J. (1960). The process of education. Cambridge: Harvard University Press.

Bruner. J. (1971). The relevance of education. New York: Norton.

Butler, J. (1951). Four philosophies and their practice in education and religion. New York: Harper.

Cajori, F. (1930). A history of elementary mathematics. New York: Macmillan.

Cuisenaire, G. \& Gattegno, C. (1961). Numbers in colour; a new method of teaching arithmetic in primary schools. Great Britain: Heinemann Educational Books.

Dame. F. (1938). Naturalism in education-its meaning and influence. Philadelphia: Temple University.

Dantzig, T. (2005). Number: The language of science. New York: Pi Press.

Davidson, T. (1971). Rousseau and education according to nature. New York: AMS Press.

Dienes. Z. P. (1963). An experimental study of mathematics learning. London: Hutchinson.

Dooley, P. (1991). The art of writing for children: Skills and techniques of the craft. Library Journal, 116(21), 160.

Fennema, F. E., \& Romberg, T. A. (1999). Mathematics classrooms that promote understanding. Hoboken: Taylor and Francis.

Froebel, F. (1826). The education of man. New York: D. Appleton.

Froebel, F., \& Lilley, I. M. (1967). Friedrich Froebel: A selection from his writings. Cambridge: Cambridge U. P.

Fuson, K. (1990). Using a base-ten blocks learning/teaching approach for first- and second-grade place-value and multidigit addition and subtraction. Journal for Research in Mathematics Education, 21(3), 180-206.

Gerdes, P. (1991). On the history of mathematics in Africa South of the Sahara: African Mathematical Union. Newsletter \#9, Commission on the History of Mathematics in Africa. Retrieved from http://www.math.buffalo.edu/mad/AMU/amu_chma_09.html

Gladman, F. J. (1886). School work. London: Jarrold's \& Sons.

Green, M. (2008). Reversing education majors' arithmetic misconceptions with short-term instruction using manipulatives (report). The Journal of Educational Research, 101(4), 234.

Gutek, G. (1968). Pestalozzi education. New York: Random House.

Harrell, M. (2009). Using base-ten block diagrams for divisibility tests. (Investigations). Teaching Children Mathematics, $15(6), 370$.

Herrera, T. (2001). The "new new math"?: Two reform movements in mathematics education. Theory into Practice, 40(2), 84-92.

Hirstein, J. (2007). The impact of Zoltan Dienes on mathematics teaching in the United States. Montana Council of Teachers of Mathematics, 169-172.

Horner, V., \& Patterson, L. (2008). How Stern's structural apparatus breaks down the barriers to learning maths. Senmagazine, 35, 9697.

Howson. A. G. (1981). Curriculum development in mathematics. Cambridge: Cambridge University Press.

Kidwell, P., Ackerberg-Hastings, A., \& Robert, D. (2008). Tools of American mathematics teaching, 1800-2000. Baltimore: The Johns Hopkins University Press.

Kilpatrick, W. H. (1914). The Montessori system examined. New York: Arno Press.

Kim. (2012). The history of Mathematics Education. Humanist: South Korea.

Landman, G. (2001). History in mathematics education—as I read it. For the Learning of Mathematics, 21(3), $22-24$.

Larson, H. (2010). The Montessori method: Educating children for a lifetime of learning and happiness (Maria Montessori). The Objective Standard, 5(2), 41. 
Lesh, R. A. (1979). Applied problem solving in early mathematics learning. Unpublished working paper, Northwestern University, Evanston, IL.

Lillard, A. (2006). Evaluating Montessori education. Science, 313(5795), 1893-1894.

Lillard, P. (1973). Montessori, a modern approach. New York: Schocken Books.

Manning, J. (2005). Rediscovering Froebel: A call to re-examine his life gifts. Early Childhood Education Journal, 32(6), $371-376$.

Mock, G. (1973). Children discover arithmetic, an introduction to structural arithmetic. The Educational Forum, 37(2), $248-249$.

National Council of Teachers of Mathematics (NCTM). (2000). Principles and standards for school mathematics. Reston, VA: NCTM.

O'Connell, G. (1938). Naturalism in American education. New York: Benziger Brothers.

Piaget, J. (1968). Genetic epistemology. New York: Columbia University Press.

Pollock, S. (1962). Colour-factor mathematics. Great Britain: Heinemann Educational Books.

Post, T. R. (1977). Teachers', principals', and university faculties' views of mathematics learning and instruction as measured by a mathematics inventory. Journal for Research in Mathematics Education, 8(5), 332-334.

Post, J. F. (1995). Naturalism. In Audi, R. (Eds.), The Cambridge Dictionary of Philosophy (pp. 517-518). Cambridge: Cambridge University Press.

Punke, H. (1965). Education and naturalism. Science Education, 49(5), 494-497.

Roberts, D. (2001). E. H. Moore's early twentieth-century program for reform in mathematics education. The American Mathematical Monthly, 108(8), 689-696.

Rosen, G. (1999). Review. Naturalism in mathematics. British Journal for the Philosophy of Science, 50(3), 467-474.

Rudman, P. (2007). How mathematics happened: The first 50,000 years. Amherst, New York: Prometheus Books.

Ruth, K. S. (1926). Standard service arithmetics. The U. S.: Foresman.

Seefeltdt, C., \& Wasik, B. A. (2006). Early education: Three, four, and five-year-olds go to school. Upper Saddle River, NJ: Pearson Education.

Standing, E. M. (1959). Maria Montessori: Her life and work. Fresno, Calif.: Academy Library Guild.

Stern, C. \& Stern, M. B. (1948). Children discover arithmetic. The U.S.: Harper \& Row, Publishers, Inc.

Tare, M. (2010). Less is more: How manipulative features affect children's learning from picture books. Journal of Applied Developmental Psychology, 31(5), 395-400.

Thorndike, E. L. (1922). The psychology of arithmetic. New York: The Macmillan Company.

Villarreal, M. E., \& Borba, M. C. (2010). Collectives of humans-with-media in mathematics education: notebooks, blackboards, calculators, computers and...notebooks throughout 100 years of ICMI. ZDM Mathematics Education. 42: 49-62.

Vianna, C. (2010). History of mathematics, mathematics education: Between nothing and everything. Bolema.Boletim De Educação Matemática, 23(35), 497-514.

Wilson, G. (1919). A survey of the social and business usage of arithmetic, New York: Teachers College, Columbia University.

WiebéWiebé, E. (1969). The paradise of childhood. Springfield: Bradley.

Young, S. (1983). Teacher education: How teacher educators can use manipulative materials with preservice teachers. The Arithmetic Teacher, 31(4), 12-13. 